\title{
Mass Transfer Coefficient in The CASE OF BRAKE-UP OF A CONTINUOUS FALLING FILM
}

\author{
Džana Kadrić, Mirela Alispahić, Berina Delalić
}
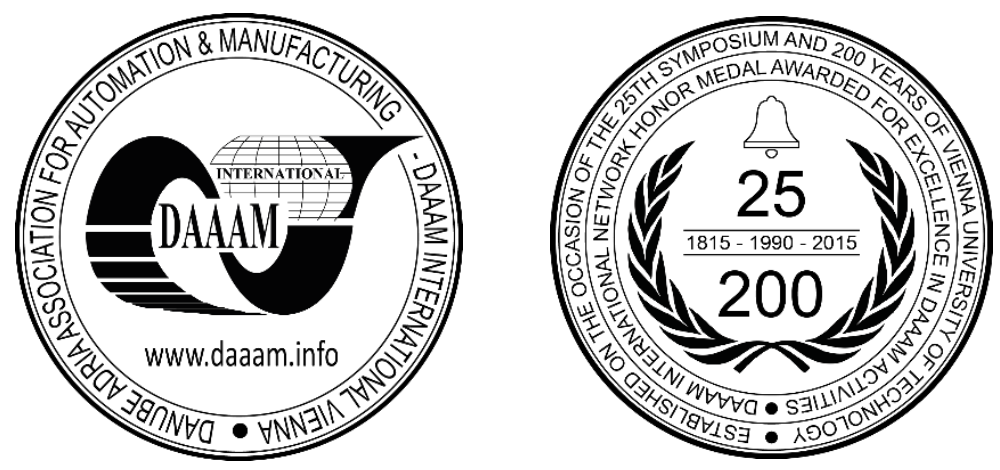

This Publication has to be referred as: Kadric, D[zana]; Alispahic, M[irela] \& Delalic, B[erina] (2016). Mass Transfer Coefficient in the Case of Brake-Up of a Continuous Falling Film, Proceedings of the 27th DAAAM International Symposium, pp.0255-0260, B. Katalinic (Ed.), Published by DAAAM International, ISBN 978-3-902734-08-2, ISSN 1726-9679, Vienna, Austria

DOI: $10.2507 / 27$ th.daaam.proceedings.037

\begin{abstract}
Two-phase flow of the thin, vertical liquid film and the counter-current air flow are studied experimentally in conditions in which liquid film brakes up. Parameters related to the two-phase flow are shown as a function of the ratio between the liquid flow rate and air flow rate and film Reynolds number. All relevant parameters change in time, so their values are shown for two time periods: when break-up starts and after a two and a half hours when final value of the degree of the wetted area is reached. Mass transfer coefficient is a function of the film Reynolds number and time, and it increases as film Reynolds number increases but decreases in time as surface de-wetting occurs. Proportion of wetted surface area as well as value of evaporated water vapour, changes as process of falling film break-up occurs.
\end{abstract}

Keywords: falling film; counter-current flow; instability; mass transfer coefficient.

\section{Introduction}

A thin, falling liquid films are encountered in many industrial applications (e.g. distillation facilities, cooling towers, vertical tube evaporators, falling film chemical reactors, food processing facilities, etc.), due to their high efficiency in heat and mass transfer. Critical conditions occur during the facility start-up, since significant amount of liquid is needed to completely cover a dry surface with continuous liquid film. When continuous liquid film is formed, it is very important to maintain the fluid minimum mass flow rate above its critical value to prevent surface to dry out. Liquid-flow rate that corresponds to these regimes is called a minimum wetting rate and the corresponding film thickness is called a minimum film thickness [1].

Theoretical models derived for prediction of the minimum wetting rate and corresponding film thickness are mostly based on two criteria: the force balance in the stagnation point and the minimum total energy of rivulets [1-5].

Breakup of the isothermal, distilled water falling film on a vertical plate in three regimes (wetting of the dry plate, rewetting and break-up of the continuous falling film) is examined in [6] and [7]. Influence of contact angle (static and dynamic) on the minimum wetting rate is confirmed as well as the influence of the plate inclination angle [7]. In the processes where air flows in counter-current or co-current to the film flow, problem is stated as a two-phase flow, and studied in many experimental and theoretical studies [8]. 
Influence of the air flow on the film brake-up process and relevant parameters has been studied theoretically in [9].

In presented experiment, influence of the counter-current air flow on the parameters related to the two-phase flow, precisely on the mass transfer coefficient, in the case of the film brake-up, is examined. Minimum flow rate for the case of the film brake-up without the air flow was very low, since measured receding contact angle is zero which is an indication of high adhesion between the plate material and the liquid. Therefore, falling film remains stable even for the very small flow rate (liquid Reynolds number smaller than 1). Results of experimental investigation for this liquid-plate material combination showed that minimum wetting rate, area of dry surface and mass transfer coefficient changes abruptly in the case of the brake-up while the counter-current air flow is introduced.

\section{Experiment setup}

The experimental setup used in the present examination is illustrated in Fig. 1. It consists of two lines: air line and the liquid line as it is shown schematically in Figure 1. These two lines were combined in test section where these two fluids in direct contact exchange mass in counter-current flow. Air was supplied from compressor.

Following equipment was installed on the air line: air cleaner, pressure regulator, flow rate regulators, and in-line flow meters. Air cleaner was installed to prevent the fouling of equipment. Pressure regulator was used to decrease pressure from 7 bars, supplied from the compressor, to the desired value. Flow rate regulators are in line with flow meters to control the air flow rate at the inlet of test section. The water feed line leads from the liquid reservoir, through the distributor towards the target surface. A laboratory pump drives the working fluid into the distributor.

In order to obtain a better spreading of the liquid over the plate, a narrow strip of filter paper was placed on the higher edge of the plate. The narrow target plate was placed vertically or inclined onto support. The stainless steel plate dimensions are $500 \times 100$ with wetted length of $410 \mathrm{~mm}$. The plate was sandblasted, with resulting average roughness given in Table 1. Working fluid was distilled water; water temperature measured at the water inlet section was $12^{\circ} \mathrm{C}$.

\begin{tabular}{|c|c|c|}
\hline Material & $\begin{array}{c}\text { Plate } \\
\text { thickness, } \mathbf{m m}\end{array}$ & $\begin{array}{c}\text { Average } \\
\text { roughness, } \boldsymbol{\mu m}\end{array}$ \\
\hline Stainless steel, X5CrNi 18-10 & 1,5 & 1,3 \\
\hline
\end{tabular}

Table 1. Plate characteristics

Experiments were carried out on a vertical upward air-water flow in a closed vertical rectangular channel. A schematic diagram of the loop is shown in Fig. 1. Experimental procedure was unified for all measurements. The plate was previously fully wetted and then the air was introduced into the channel. The water flow was set on a constant value and the air flow rate was decreased gradually in order to form a dry zone on the plate. The degree of wetted plate surface was observed for two and half hours, as it takes for one complete measuring procedure. Mass transfer takes place in direct contact while the fluids flow in countercurrent.

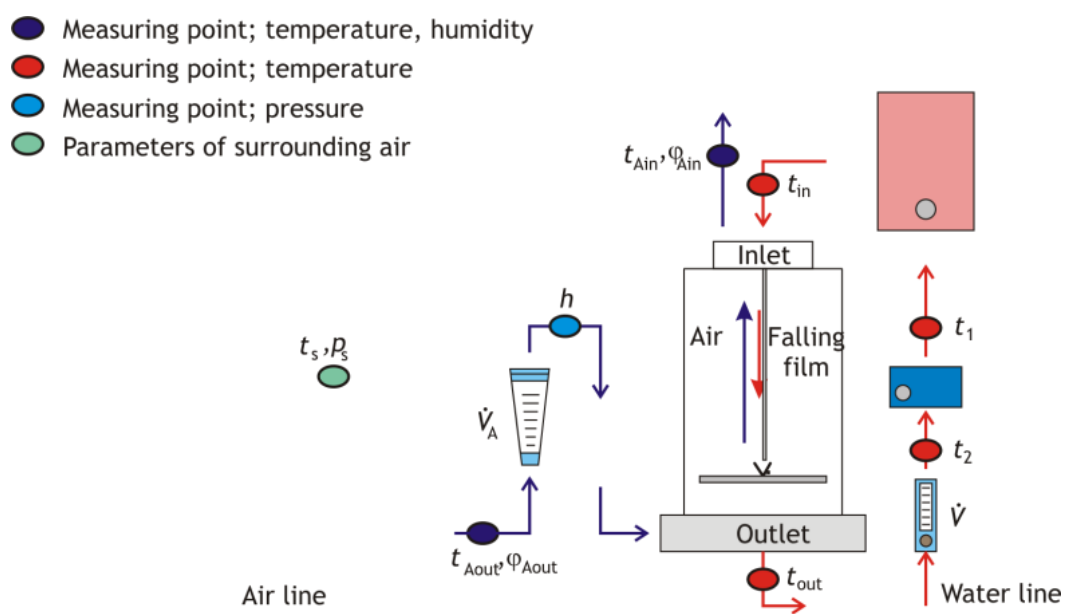

Fig. 1. Experimental setup

\section{Flow hydrodynamics (observation)}

Developed experiment procedure ensured analysis of the impact of fluid flow and air flow reduced to standard conditions on wetted surface, defined as the ratio of wetted to the overall plate surface. 
The flow corrected to standard conditions is calculated from the flow measured on the flowmeter, as:

$$
\dot{V}_{\mathrm{A}, \mathrm{s}}=\dot{V}_{\mathrm{A}} \sqrt{\frac{p_{\mathrm{A}, \text { out }}+p_{\mathrm{at}}}{1,013} \frac{288,15}{173,15+t_{\mathrm{A}, \text { out }}}}
$$

where $\dot{V}$ is the volumetric air flow rate measured on the flowmeter, $p_{\mathrm{A}, \mathrm{out}}$ is the pressure at the inlet of the test section, $p_{\text {at }}$ is the atmospheric pressure and $t_{\mathrm{A}, \text { out }}$ is the temperature at the inlet of the flowmeter, as marked in Fig. 1. Pressure $p$ at the exit of the flowmeter is measured using the water manometers ( $U$-tube).

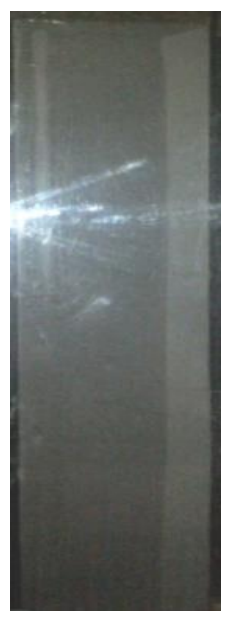

a)

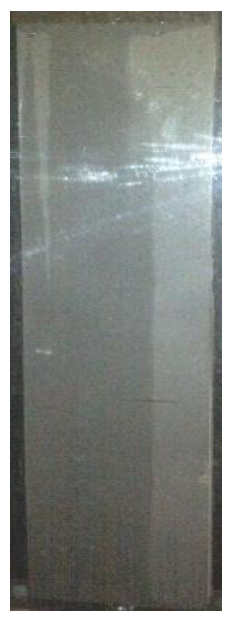

b)

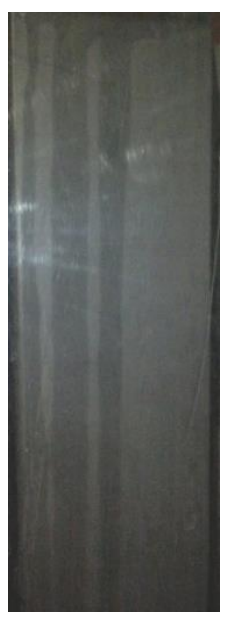

c)

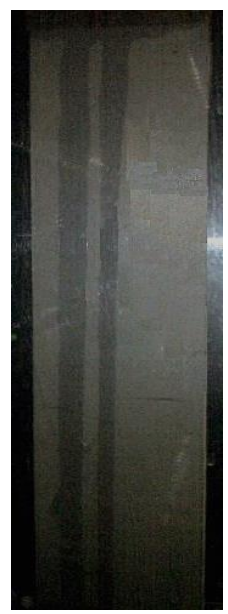

d)

Fig. 2. Plate dry out over time: water flow rate $1 \mathrm{ml} / \mathrm{min}$ and mean air velocity $u_{\mathrm{A}}=0,566 \mathrm{~m} / \mathrm{s}$ (duration of the experiment $\tau=2,5 \mathrm{~h}$ )

In Fig. 2. a set of measurements is showed. Liquid flow rate was constant $1 \mathrm{ml} / \mathrm{min}$, which represents flow rate above minimum wetting rate for conditions without air flow rate. Duration of measurement was two and a half hours. When air is supplied in to a test section plate, de-wetting occurs rapidly (Fig. 2a.). De-wetted area increases in time which can be noticed in Fig. 2 (b-c)., and finally two narrow rivulets are formed as it is shown in Fig. 2.d.

The degree of the wetted surface is a function of the time needed to carry out the complete measuring procedure, as in Fig. 2. In order to ensure stable state and parameters it was concluded that the time could not be less than two and half hours.

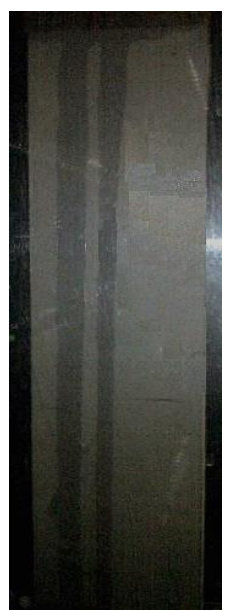

Liquid flow rates: a) $1 \mathrm{ml} / \mathrm{min}$

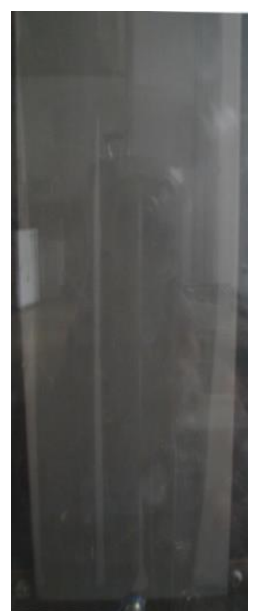

b) $1,7 \mathrm{ml} / \mathrm{min}$

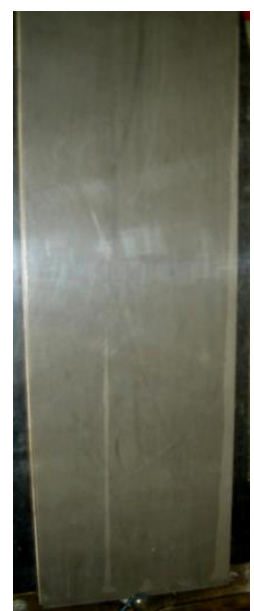

c) $2,4 \mathrm{ml} / \mathrm{min}$

Fig. 3. Wettability of the plate for different volumetric liquid flow rates and mean air velocity $u_{\mathrm{A}}=0,552 \mathrm{~m} / \mathrm{s}$

Fig. 3. shows significant impact of the liquid flow rate on the degree of the wetted surface. It is noticeable that with increase of the liquid flow rates the degree of the wetted surface is increasing for the same air flow rate. For smaller water flow rates, only about $30 \%$ of the plate was wetted. This small percentage of the wetted surfaces for small flow rates 
confirms previous observations on liquid microfilm covering blasted hydrophilic surface of the plate, which dries out as soon as the air flow starts. Mean air velocity in the test section ranged from $0,548 \mathrm{~m} / \mathrm{s}$ to $0,736 \mathrm{~m} / \mathrm{s}$.

\section{Analytical considerations}

For a two-phase flow consideration, dimensionless numbers are used: Sherwood number as a representative of the mass transfer and Reynolds number as a representative of the flow hydrodynamics. Similar experiments conducted on this experimental line showed that sensible heat transfer is significantly smaller than latent heat transfer which resulted in a following relationship [10]:

$$
\mathrm{Sh}=\frac{\beta D_{m}}{M c \boldsymbol{D}}=0,66 \mathrm{Re}_{\mathrm{A}}^{0,69} \mathrm{Re}^{0,27}
$$

where $\beta$ is the mass transfer coefficient, $D_{\mathrm{m}}$ is the characteristic mass transfer diameter, $M$ is the molecular weight for the water vapor, $c$ is the molar concentration and $\boldsymbol{D}$ is the diffusion coefficient which is calculated as:

$$
\boldsymbol{D}=1,97 \cdot 10^{-5} \frac{p_{0}}{p}\left(\frac{T}{T_{0}}\right)^{1,685}
$$

which is suitable for $273<T<373 \mathrm{~K}$, where $p_{0}=1$ atm and $T_{0}=256 \mathrm{~K}$.

Reynolds numbers for air and falling film are defined as:

$$
\operatorname{Re}_{\mathrm{A}}=\frac{u_{\mathrm{A}} D_{\mathrm{h}}}{v_{\mathrm{A}}}, \operatorname{Re}=\frac{4 \gamma}{\mu}
$$

respectively, where $D_{\mathrm{h}}$ is the hydraulic diameter, $O_{\mathrm{h}}$ is the wetted perimeter, $u_{\mathrm{A}}$ is the mean air velocity, $v_{\mathrm{A}}$ is the kinematic viscosity and $\gamma$ is liquid flow rate per unit perimeter.

\section{Results and discussion}

In Fig. 4. degree of the wetted surface is shown as a function of the ratio of liquid to air flow rates. It is noticeable that increase of liquid to air flow ratio results in an increase of the degree of the wetted surface. It is noticeable that, for ratio higher than 2,8, portion of wetted surface remains very high. For smaller ratios, portion of the wetted surface is small which certainly adverse process of the heat and mass transfer.

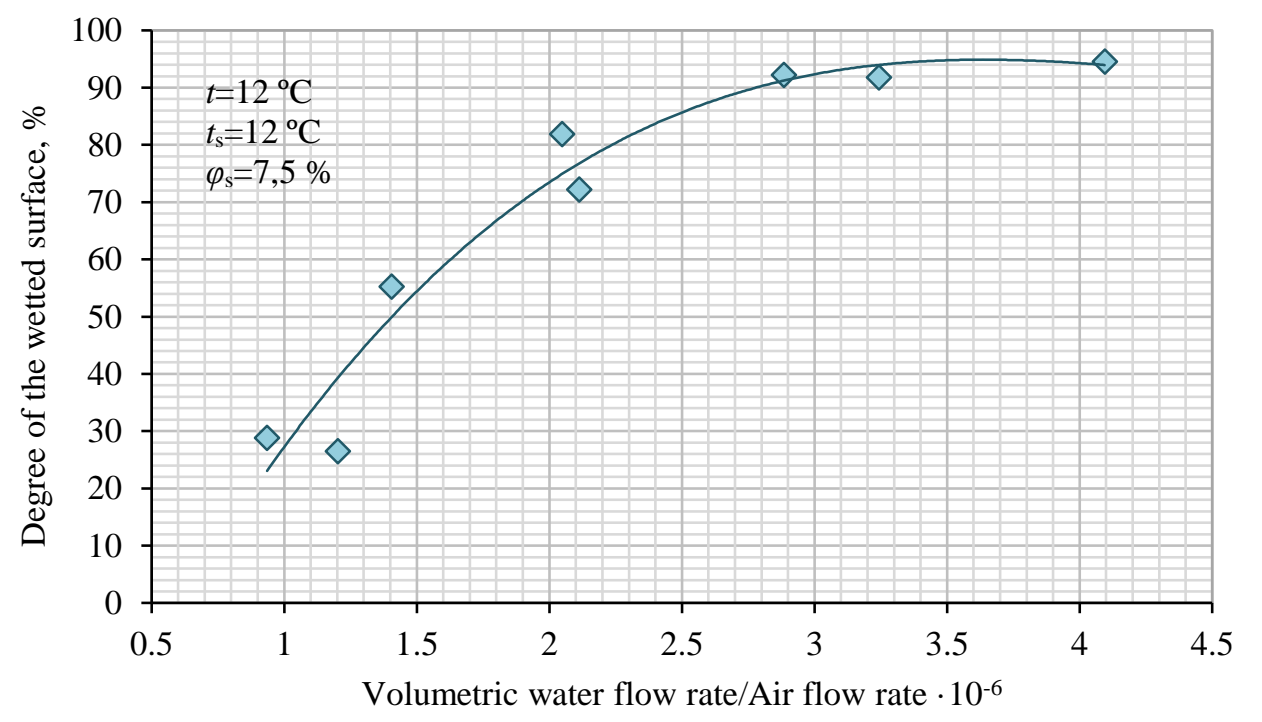

Fig. 4. The degree of the wetted surface in terms of the ratio of liquid to air flow rates

Values of mass transfer coefficient, calculated from Eq. (2) changes in time, as it is shown in Fig. 5. When measurements start, mass transfer coefficient trend is practically constant, with small deviations, as film Reynolds number 
changes. Contact area between air flow and liquid film is approximately equal for all starting measurements since whole plate is covered with thin liquid film. While plate de-wetting occurs and air wetted perimeter decreases, mass transfer coefficient decreases, especially for small film Reynolds numbers. For film Reynolds number higher than 1,5 mass transfer coefficient approaches initial value and shows that it is not a function of time.

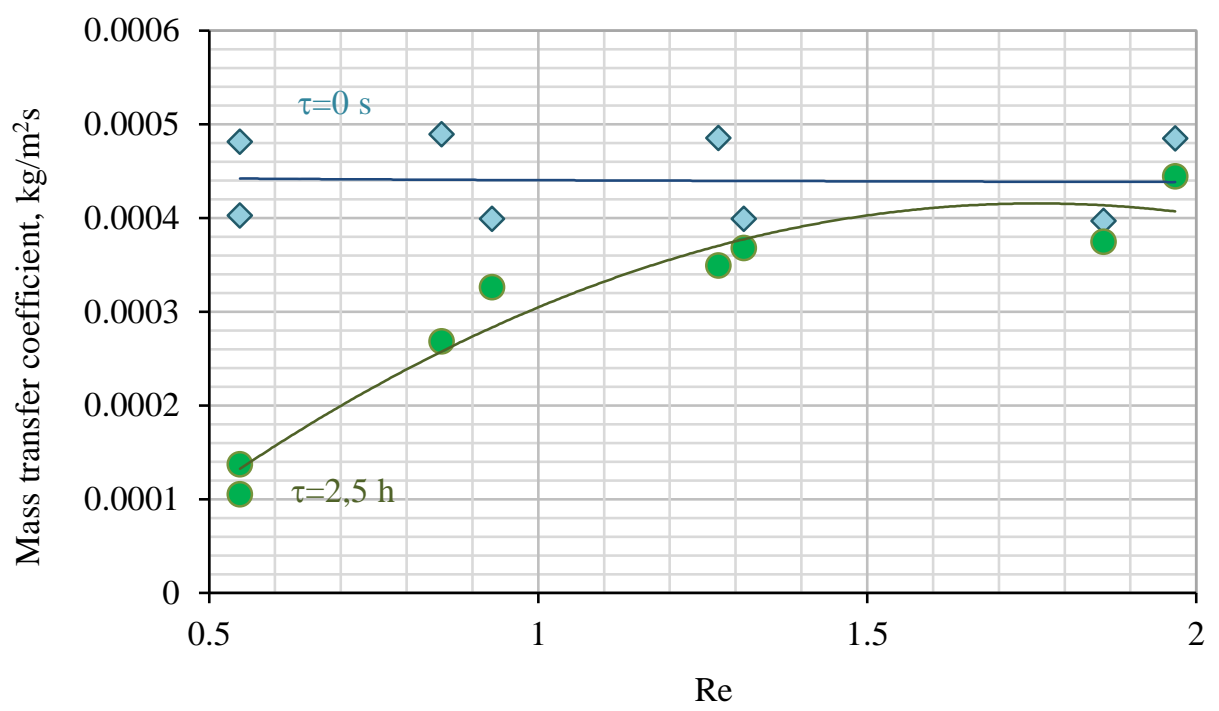

Fig. 5. Mass transfer coefficient in terms of the liquid film Reynolds number

Using the values of mass transfer coefficient, percentage of evaporated liquid in the net liquid flow is calculated and shown in terms of ratio of liquid to air flow rates in Fig. 6. For small ratio when measurements start, evaporated liquid ratio is very high and it decreases in time, since large portion of plate is de-wetted and liquid-air interface decrease abruptly. For higher ratio of liquid to air flow rates, percentage of evaporated liquid remains constant in time and has the value of about $30 \%$.

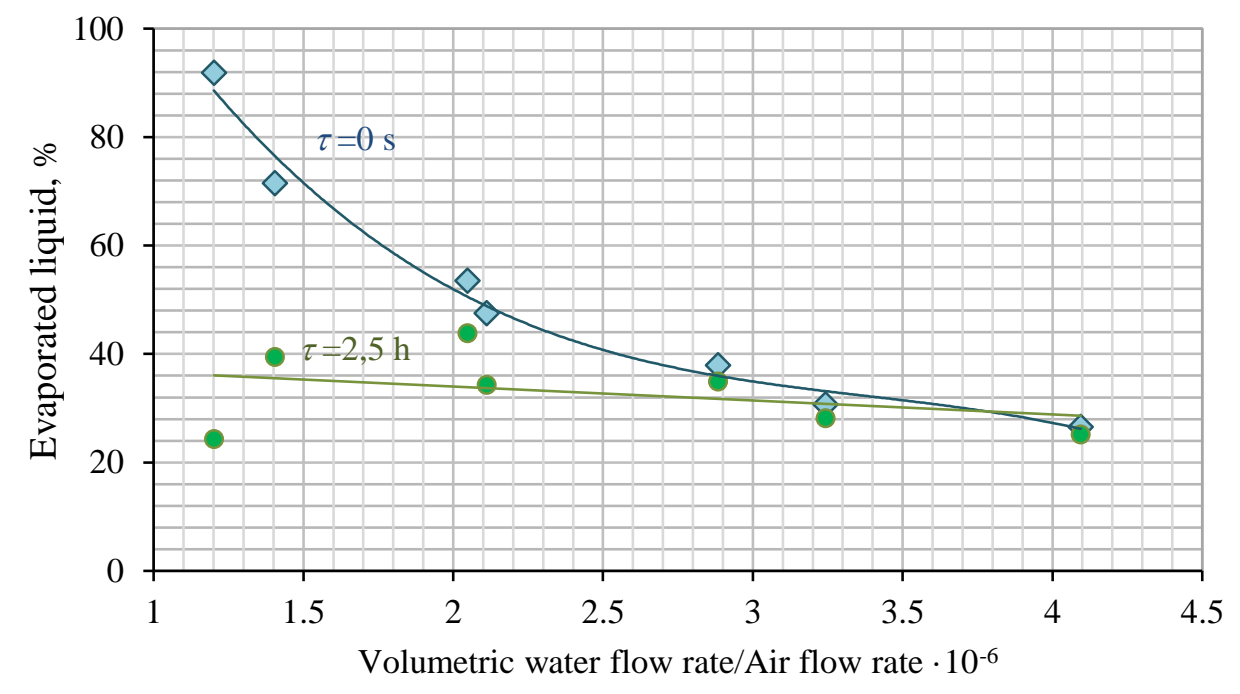

Fig. 6. Percentage of the evaporated liquid in net liquid flow in terms of the ratio between the volumetric flow rates

\section{Conclusions}

of liquid and air.

Results of experimental investigation of two-phase flow parameters for conditions where film brake-up occurs, are presented. Thin liquid film is formed on the vertical plate. Minimum flow rate for the case of the film brake up without the air flow was very low, since measured receding contact angle is zero which is an indication of high adhesion between the plate material and the liquid. Therefore, falling film remains stable even for the very small flow rate (liquid Reynolds number smaller than 1). 
Results for tested liquid-plate material combination showed that area of dry surface and mass transfer coefficient changes abruptly when counter-current air flow is introduced. All relevant parameters changes in time, so their values are shown for two time periods: when break-up starts and after a two and a half hour when final value of the degree of the wetted area is reached. It is shown that ratio of liquid to air flow rate can be included in to a consideration, so important two-phase flows parameters can be shown in term of this ratio. Since, ratio of liquid flow rate to air flow rate vas in the range of 1,2 to $4,2 \cdot 10^{-6}$, air humidity and temperature change within the test section could not be measured. Therefore, relation for Sherwood number and air and falling film Reynolds number is taken from the similar experiments conducted on the same experimental line. This ensures that mass transfer coefficient could be evaluated and presented as a function of the film Reynolds number and time. Results shows that it increases as film Reynolds number increases but decreases in time as surface de-wetting occurs. Proportion of wetted surface area as well as value of evaporated water vapour, changes as process of falling film break-up occurs.

It is shown that for ratio of liquid to air flow rates higher than 2,8 , portion of wetted surface remains very high and portion of evaporated liquid remains constant in time. For smaller ratios, portion of the wetted surface that is interface between liquid film and air flow is small which adverse process of the heat and mass transfer. Also, while plate de-wetting occurs and air wetted perimeter decreases, mass transfer coefficient decreases, especially for small film Reynolds number. For film Reynolds number higher than 1,5 mass transfer coefficient does not change in time significantly.

Presented experiments were conducted in a specific condition; plate-liquid material with resulting zero receding contact angle and high adhesion forces. For different plate surface treatments, other contact angles and liquid flow rates for film brake-up are measured. It would be very useful to conduct similar experiment on plates from other materials and surface treatments, to investigate the mass transfer coefficient and liquid evaporate rate in presence of counter-current air flow.

\begin{tabular}{|c|c|c|c|}
\hline \multicolumn{5}{|c|}{ Nomenclature } \\
\hline$c$ & Molar concentration $\left[\mathrm{mol} \mathrm{m}^{-3}\right]$ & $D$ & Diffusion coefficient $\left[\mathrm{m}^{2} \mathrm{~s}^{-1}\right]$ \\
\hline$D_{\mathrm{h}}$ & Hydraulic diameter $[\mathrm{m}]$ & $D_{\mathrm{m}}$ & Characteristic mass transfer diameter $[\mathrm{m}]$ \\
\hline $\mathrm{M}$ & Molecular weight for the water vapor $\left[\mathrm{kg} \mathrm{mol}^{-1}\right]$ & $p$ & Pressure [bar] \\
\hline$O_{\mathrm{h}}$ & Wetted perimeter $[\mathrm{m}]$ & $\mathrm{Re}$ & Reynolds number \\
\hline$t T$ & Temperature $\left[{ }^{\circ} \mathrm{C}, \mathrm{K}\right]$ & $\mathrm{Sh}$ & Sherwood number \\
\hline$\dot{V}$ & Volumetric flow rate $\left[\mathrm{m}^{3} \mathrm{~s}^{-1}\right]$ & $u$ & Velocity $\left[\mathrm{m} \mathrm{s}^{-1}\right]$ \\
\hline$\gamma$ & Mass flow rate per unit perimeter $\left[\mathrm{kg} \mathrm{m}^{-1} \mathrm{~s}^{-1}\right]$ & $\beta$ & Mass transfer coefficient $\left[\mathrm{kg} \mathrm{m}^{-1} \mathrm{~s}^{-2}\right]$ \\
\hline$v$ & Kinematic viscosity $\left[\mathrm{m}^{2} / \mathrm{s}\right]$ & $\mu$ & Dynamic viscosity $\left[\mathrm{N} \mathrm{s} \mathrm{m}^{-2}\right]$ \\
\hline$\varphi$ & Relative humidity $[\%]$ & $\tau$ & Time $[\mathrm{s}]$ \\
\hline \multicolumn{2}{|c|}{ Abbreviations } \\
\hline A & air & at & atmospheric \\
\hline in & inlet & out & outlet \\
\hline $\mathrm{s}$ & surrounding & & \\
\hline
\end{tabular}

Table 2. Nomenclature and abbreviations

\section{References}

[1] M.S. El-Genk and H.H. Saber(2001). Minimum thickness of a flowing down on a vertical surface, Int. J. Heat Mass Transfer, 44:2809-2825

[2] D.E. Hartely, W. Murgatroyd(1964). Criteria for the break-up of thin liquid layers flowing isothermally over solid surface, Int. J. Heat Mass Transfer, 7: 1003-1015

[3] T. Hobler (1964). Minimum surface wetting, Chem. Stosow, 2B:145-159

[4] S.G. Bankof (1971). Minimum thickness of a draining liquid film, Int. J. Heat Mass Transfer, 14:2143-2146

[5] J.Mikielewicz and J.R. Moszynski(1976). Minimum thickness of a liquid film flowing vertically down a solid surface, Int. J. Heat Mass Transfer, 19:771-776

[6] D. Moalem-Maron, N. Brauner (1983). Transport characteristics of wavy thin films on inclined surfaces, Advance in Two-Phase flow and Heat Transfer, Vol. 1:155-181

[7] Dž. Kadrić, M. Alispahić, Š. Šikalo, S. Jakirlić and E. N. Ganić (2015), E181, Proceedings of the Eight International Symposium on Turbulence, Heat and Mass Transfer, K. Hanjalić, T. Miyauchi, D. Borello. M. Hadžiabdić, P. Venturini (Editors); ISBN: 978-1-56700-428-8, Begell House Inc.

[8] Šikalo, Šefko; Berberović, Edin (2014). Analysis of Droplet Deposition in a Vertical Air-Water Dispersed Flow, Proceedings of the 25th DAAAM International Symposium, pp.xxxx-xxxx, B. Katalinic (Ed.), Published by DAAAM International, ISBN 978-3-902734-08-2, ISSN 1726-9679, Vienna, Austria

[9] M.S. El-Genk, H.H. Saber(2004). On the break-up of thin liquid film subject to interfacial shear, J. Fluid Mech. 501:113-133

[10] Kadrić, Dž., Šikalo, Š., Delalić, N. and Ganić, E.N. (2007). Experimental investigation of a laminar falling film, 6th International Conference on Multiphase Flow,ISBN 978-3-86010-913-7 